\title{
Exploring Intercultural Communication in Expats' Social Media Groups
}

\author{
ZeynepAksoy \\ University of Amsterdam, Amsterdam School for Regional, Transnational and European Studies
}

\begin{abstract}
As international and global organizations grow, so the expatriate communities expand in different regions of the world. Professionals, who are assigned to positions abroad by multinational/international organizations, constitute a multicultural community in which they face similar challenges of settling in, adjusting and joining in social life in a new culture. Since digital communication technologies provide virtual spaces for interaction, expats are more likely to find opportunities to meet others who share common difficulties and expectations. Thus, online social networks enable a so-called interactive area for expats to communicate and share news, opinions or experiences. This study attempts to understand the intercultural communication themes of expat communities in social media groups. With this aim, Facebook groups of two expat communities, "Expats in Istanbul" and "Expats in Amsterdam", have been examined through qualitative content analysis. Qualitative approach enhanced developing an insight into the meaning and the process of communication. The postings, shared on Facebook groups in March 2016, are investigated based on an open coding process. The study results demonstrate that members tend to use these social network groups with 'survival' concerns within the context of intercultural relationship.
\end{abstract}

Keywords:Expatriate, social media group, social network, intercultural communication

\section{Introduction}

Mobility of human being has always been a reality throughout the history, however it has obviously accelerated since development of means of communication and transportation in industrial age. Moreover, rapid development of information communication technologies after 1970s has relatively eased the mobility.Increased economic, political and social interconnection across the world, which is labelled as globalization, leads increased number of people to move from their countriesto others, individually or massively. The reasons of human mobility vary from environmental disasters to political conflicts, which often force people to flee from their homes to safer regions. On the other hand, individuals are also motivated by better jobs, better life conditions for themselves and their families, and carrier development to move in different countries.

As corporates expand their functions in different regions of the world, professionals find opportunities to work and live in places other than their home countries. Today, these professionals are generally called as expatriates- briefly as expats. General usage of the term refers to "anyonewho is living and working in a foreign country" (Huff, 2013, p. 597). More specifically,expat is defined as "those who are either on short-term intracompany transfers or working for international companies for the longer term"(Von Koppenfels, 2014, p.23).Zhang (2012) defines expat as "someone sent by organizations to manage or cooperate with others on international assignment for at least 6 months, including wide professional coverage of multinational corporations (MNCs), transnational corporations (TNCs), multinational organizations (MNOs), and smaller companies involving different industry sectors" (p. 179). Thus, it can be understood from the literature that the term expat is generally used for individuals who are assigned to work and live in a foreign country.

Since the field of intercultural communication emerged in the 1950s with the first studies of Edward T. Hall (1959), researches on expatriates have become a prominent area for scholars examining different aspects of international mobility (Hammer, Gudykunst and Wiseman, 1979; Tung, 1981; Tung, 1993; Caligiuri, Tarigue and Jacobs, 2009; Rockstuhl et. al., 2011; Clausen et. Al., 2009; Koh, Joseph and Ang, 2009; Huff, 2013). Furthermore, enhancing the mobility by reducing the dependence on time and space, development of information communication technologies impactsintercultural communication. A review of literature reveals that interconnection between new media and intercultural communication has been approached by investigating the usage of social media applications by multicultural groups (McEwan and Sobre-Denton, 2011), the impact of 
social media in foreign language education (Batardière, 2015; Brooks and Pitts, 2015; Lang, 2010), the process of collaborative information seeking in intercultural computer-mediated communication (Cho and Lee, 2008), the impact of intercultural communication project on eliminating stereotypes and biases (Devran, 2010), cultural aspects of online communication (Seidenspinner and Theuner, 2007; Toyokawa, 2006; McEwan and SobreDenton, 2011), the effect of virtual environment on intercultural sensitivity (Coffey et.al, 2013), interpersonal communication (Wang, Walther and Hancock, 2009) and cross-cultural collaboration (Wang, 2012) in virtual networks.

Chen (2012) explores the impact of new media on intercultural communication through drawing a framework for researchers that includes three emerging areas: 1) the impact of culture on the development of new media, 2) the impact of new media on cultural identity, and 3)the impact of new media on intercultural interaction (p.4). Within this framework, this study aims to investigate how members of different cultures communicate in a social media group in order to understand intercultural relationship in social media.

\section{Intercultural Communication and Social Media}

Intercultural communication is a multidisciplinary field that investigates the interaction between members of different cultures, and seeks solutions for issues, which may occur during these interactions.Researches vary from cultural diversity (Tung, 1993; Stahl et. al, 2010) to individual competences (Spitzberg, 2000; Deardorff, 2006; Collier, 2015). Rooted back to mid-twentieth century, the field has been facing challenges and opportunities of globalization. In a world where the concepts of time and space are reconsidered, interaction between people from diverse cultural backgrounds moves to a new state of existence. Intercultural communication, which was formerly a unique field of interest for diplomats, becomes a topic for many individuals and institutions, from ordinary tourists to multinational corporations. Today, growing economic relations across countries and regions lead business organizations involve in mobilized human capital. Therefore, success in different culturesfor highly-skilled employees and managers is emphasized as one of the most important subjects in organizations that are engaged with intercultural communication concepts. This issue is generally related with expatriate's cross-cultural adjustment (Zhang, 2012). Farhet. al (2010) points out that the success of expatriates is largely connected with their abilities of adjustment to work and non-work conditions in the host culture (p.434). In this respect, network ties in the host city or country become a major concern for expats in order to receive social support. By means of online communication, especially social media including wikis, forums, blogs, micro blogs and social network sites (SNS), expats find opportunities to develop social networks in new places. When social network ties are taken in consideration for expatriate adjustment, SNS play a distinguished role resulting from their prevalence and popularity.

Reporting 1.59 billion monthly active users as of December 2015(http://newsroom.fb.com/company-info/), leading SNS Facebook allows users to share personal information and communicate with others (Shelton and Skalski, 2013, p. 339). Moreover, it provides a virtual and interactive space to disseminate photos, videos, opinions, and news stories, to advertise, and grow business. Having a Facebook account is not exclusive to individuals. For-profit and non-profit organizations, political parties and activist groups have already discovered the impact of social media and become members of this popular SNS forsharing content, building network, and communicating with stakeholders. As individuals and organizations are relatively more connected through SNS, many expats use them as a virtual space of connection with others who are supposed to have similar experiences and expectations in the host culture. The study of Farh and others (2010) brings forth a model of tie formation that identifies motivation factors of expats for seeking informational and emotional support from other actors who have expertise in the host country (p.441).

Social media usage of international professionals emphasizes the necessity to merge intercultural studies with online communication studies. Shutter (2012) proposes an inclusive study fieldof Intercultural New Media Studies, which focuses on the impact of new media on intercultural communication, and describes five areas of investigation: cultural identity, intercultural dialogue, third culture, acculturation, and intercultural competence (p.221).Chen (2012) puts forth that existing research on relationship between new media and intercultural communication highlights three different aspects of intercultural interaction: intercultural relationship, intercultural adaptation, and intercultural conflict. According to Chen (2012), new media affects the development of intercultural relationships in the virtual community through the creation of a network 
(p.5).Intercultural relationship can be established by online interaction between users. Furthermore, these virtual networks can help individuals to sustain intercultural relationship in real life.

\section{Methodology}

Aiming to understand intercultural relationship in social media, this study attempts to explore communication themes of expats in online social network groups, which are specifically created for developing interaction among expats in a host city or a country. With this aim, the research question is constituted as follows: What are the communication purposes of expats in social media groups?

Researches in intercultural communication and management concentrating on expatriates vary in their methods as both quantitative (Black, 1990; Caligiuri, 2000; Graf and Harland, 2005; Stening and Hammer, 1992) and qualitative (Deng and Gibson, 2008; Peltokorpi, 2010) methods are used. On the other hand, diverse techniques of media and communication researches, particularly in qualitative approach, can also be used in intercultural studies. This study adopts qualitative content analysis method in order to gain an insight into the communication themes in expats' social media groups.

Being a frequently used method in communication research, content analysis offers researchers to make sense of broad documents and reveal certain representations. Kolbe and Burnett (1991) defines content analysis as "an observational research method that is used to systematically evaluatethe symbolic content of all forms (image, word or roles) of recorded communication (p. 243). Krippendorff (1989) defines content analysis as "a research technique for making replicable and valid inferences from data to their context" (p. 403). The purpose is to identify frequently repeated concepts in a selected data and associate them with the related phenomenon, research question or theory (Hsieh and Shannon, 2005; Elo and Kyngas, 2007).Content analysis is often used within a quantitative approach (Semetko and Valkenburg, 2000; Shelton and Skalski, 2014)that embraces a statistical technique relying on explicit definitions of categories, in which words, phrases or visual unitsare counted. Nonetheless, content analysis is also used as a qualitative research technique in communicationstudies (Marsh and White, 2006).

Qualitative content analysis focuses on the communication in terms of the contextual meaning of the text, and goes beyond counting pre-determined words (Hsieh and Shannon, 2005, p. 1278). Krippendorff (2004) emphasizes the necessity of analysing textual materials in more unstructured ways that lead researchers to focus on relevant parts of the text as a representative example for their studies (p.788). In this respect, qualitative approach can be accepted as a relatively more flexible technique. Qualitative content analysis is conducted with an inductive approach by moving from specific to general, when knowledge about the phenomenon is insufficient (Elo and Kyngas, 2007; Hsieh and Shannon, 2005; Marsh and White, 2006). Hereby,contextual meaning is derived from the data through open coding process to the contrary of searching out previously defined concepts. Inductive process of qualitative content analysis serves to reach to an interpretationof the meaning in communication.

This study takes the advantage of inductive approach in qualitative content analysis, which enables to gain manifest information form electronic text "without imposing preconceived categories or theoretical perspectives (Hsieh and Shannon, 2005, p.1280)".In relation with the research questions, purposive sampling was applied, and two Facebook groups were chosen based on their referred cities (Istanbul and Amsterdam), virtual accessibilities and open membership systems.The analysing process begins with open coding through reading the text and taking the first notes that may correspond to certain categories after second and third readings. Firstly, the Facebook group called "Expats in Istanbul"was examined, and the postings between March 1 and March 30, 2016, were read to classify them into smaller categories. Hsieh and Shannon (2005) explains inductive category development as a procedure of reading the data word by word and finding out common themes or concepts that are highlighted most frequently by the source. Therefore, the data were read over again to group codes in meaningfulcategories. Same procedure was followed to examine the Facebook group called "Expats in Amsterdam" through reading the postings in March 2016. This second data group was used to crosscheck codes and categoriesthat are found in first data group. Examination of the second Facebook group was ended once the number of postings was reached over double of the first Facebook group's postings.

The major concerns in qualitative content analysis are validity and reliability. Although, this method is not used with an aim of putting forth generalizations in objective ways, qualitative studies are required to be 
systematic as well. Marsh and White (2006, p. 38, cited from Lincoln and Guba, 1985) summarize four categories of trustworthiness, which are credibility, transferability, dependability and confirmability. Accordingly, internal and external validity can be realized with credibility and transferability, while reliability can be formed with confirmability. Inter-coder reliability, which has a greater importance in quantitative content analysis, is replaced with confirmability in qualitative content analysis that refers to "confirmation of findings by looking at the data, not the researcher(s), to determine if the data support the conclusions" (Marsh and White, 2006, p. 38). In this study, examination of two social media groups provided the researcher to crosscheck codes and categories on comparable data sources in order to enhance transferabilityof the study.

\section{Findings}

In performing the qualitative content analysis on Facebook groups, firstly an open coding process was conducted over the postings. Once preliminary coding system was developed, frequencies of each codewere counted in order to have an overview about the communication topics. Through repeated examination of the data, coding system is finalized including the frequencies (Table I and Table II).

TABLE 1. Codes and Frequencies ofFacebook group content - Expats in Istanbul

\begin{tabular}{lll}
\hline \hline Code & Frequency & $\%$ \\
\hline Event & 82 & 48,24 \\
Flat/room for rent & 24 & 14,12 \\
Flat/room to rent & 3 & 1,76 \\
Seeking staff & 8 & 4,71 \\
Job search & 1 & 0,59 \\
Language learning & 8 & 4,71 \\
Business advert & 7 & 4,1 \\
Social/cultural/sportive activity & 7 & 4,12 \\
Enquiry of recommendation & 2 & 1,18 \\
Survey & 1 & 0,59 \\
Legal matters & 1 & 0,59 \\
Share of posting & 9 & 5,29 \\
Share of photo & 14 & 8,24 \\
Others & 3 & 1,76 \\
Total & 170 & 100 \\
\hline \hline
\end{tabular}

TABLE 2. Codes and Frequencies of Facebook group content - Expats in Amsterdam

\begin{tabular}{lll}
\hline \hline Code & Frequency & $\%$ \\
\hline Event & 50 & 14.3 \\
Flat/room for rent & 18 & 5.14 \\
Flat/room to rent & 16 & 4.57 \\
Short-term stay flat/room & 4 & 1.14 \\
Flat for sale & 1 & 0.29 \\
Enquiry of recommendation & 33 & 9.43 \\
Sales (bike, goods, products) & 32 & 9.14 \\
Question & 30 & 8.57 \\
Seeking staff & 19 & 5.43 \\
Job search & 9 & 2.57 \\
Business advert & 24 & 6.86 \\
Social/cultural/sportive activity & 15 & 4.29 \\
Language learning & 10 & 2.86 \\
Survey & 1 & 0.29 \\
Legal matters & 11 & 3.14 \\
Share of posting & 29 & 8.29 \\
Share of photo & 14 & 4 \\
Share of video & 8 & 2.29 \\
Others & 26 & 7.43 \\
Total & 350 & 100 \\
\hline \hline
\end{tabular}

Coding system of the first examined social network group (Expats in Istanbul) revealed that the main communication themes of members include event organizations, rental flat announcements or flat seeking, 
searching for job or staff, and business adverts. Besides, members share postings of different sources, which generally include texts about travelling, and photos of completed events. Other communication themes include language learning (i.e. language lessons, courses or groups), announcements about social, cultural or sportive activities, and asking recommendations or questions regarding legal matters or health support.

Second social network group (Expats in Amsterdam), which is used for crosschecking the preliminary codes derived from the first social network group, demonstrated similar communication themes, although they have different weights in overall topics. For example event organizations take part in members' communication themes, while their share remain under 15\%. Second data group includes different themes such as sales (bikes, furniture, goods, products), questions, share of videos, and other topics (i.e. enquiry of project partner, accountant, interviewees or friends).

Following the identification of preliminary codes in both social network groups, related codes are sorted into categories(Figure I). Inductive category system was organized according to the abstraction process suggested by Elo and Kyngas (2007, p. 111). This process allowed researcher to generate codes within broad categories for making sense of the content shared in social network groups of expats.

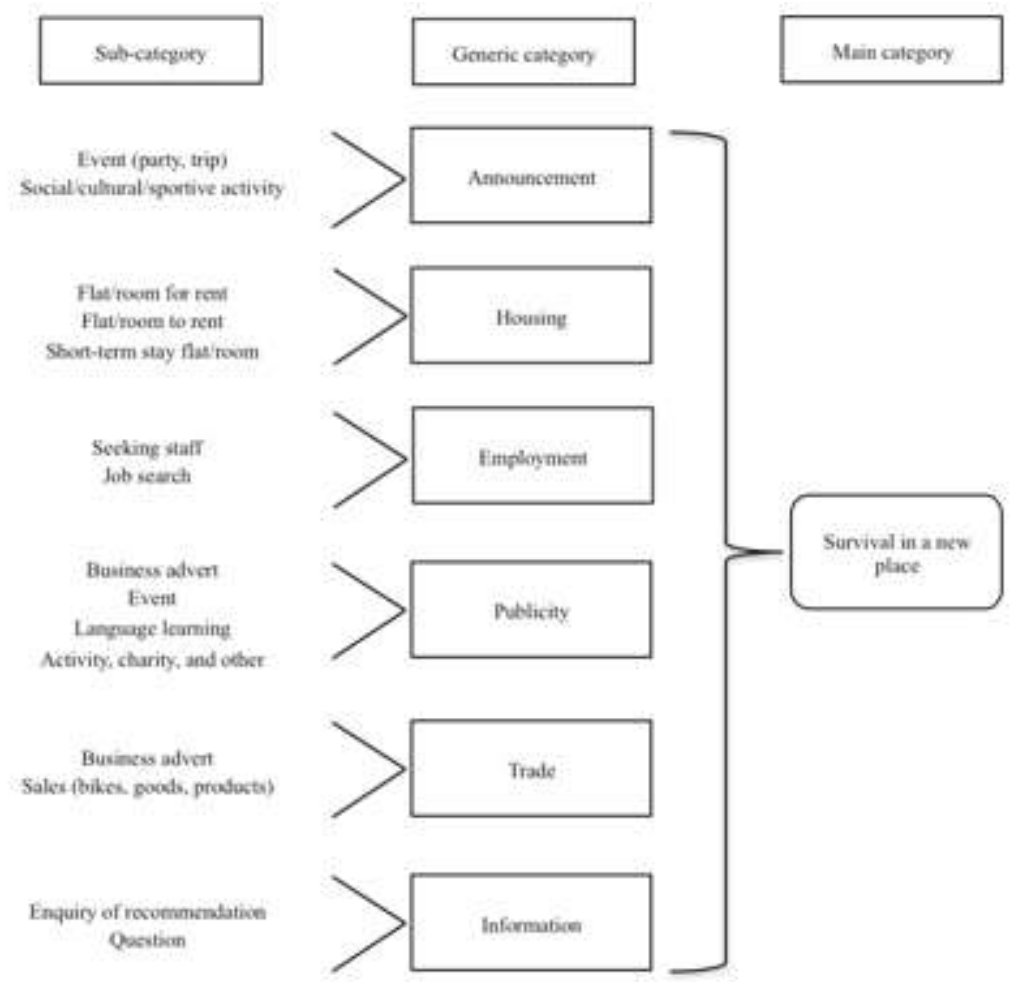

Fig. 1. Categorization and Abstraction Process

Repeated examination of both data group's content provided the identification of sub-categories, which is followed by collecting them in generic categories. Content of the expats' Facebook groups are generated in six categories: announcement, housing, employment, publicity, trade and information. This category system puts forth main communication themes of the members. In other words, purpose of communication in related social media groups are described as follows:

1. Announcement: Members aim to disseminate the information about upcoming event organizations, excursions, sightseeing tours, and activities, which may encourage members to interact with each other offline.

2. Housing: As members are the foreigners who live in a new country, they often become a part of real estate market. Thus, renting out and seeking for flats/rooms, seeking for flatmate are one of the main communication topics of the members.

3. Employment: As members are also a part of the labour market, they use the Facebook group as a medium for human resources, in which they either post job or seek job. 
4. Publicity: Facebook groups are highly used for adverts in various fields, but mainly for business that is carried out individually or as corporate. Language lessons/courses, charity organizations, and other activity initiatives also use this channel for publicity.

5. Trade: Members use the groups for advertising and sales activities for several goods and products, where they post detailed information, photo and price.

6. Information: Members ask questions that they search for opinions and recommendations of the other members.

Abstraction process is completed through embracing generic categories with one broad category that is hereby called as "survival in a new place". Described as "to remain in existence" (http://www.dictionary.com/browse/survive), the concept of survival is used heremore in ametaphorical way. Interpretation of categories reveals that the content of communication in expats' social media groups essentially corresponds with survival matters in anew environment.

\section{Discussion and Conclusion}

Social media -or the new media, has been transforming interpersonal interactions for a while. Today, people who have Internet access can easily reach to social media tools varying from micro blogs to social networks. Being the leader of SNS, Facebook gathers individuals or organizations by connecting them through a digital network that enables simultaneity in a certain extent. Although this simultaneity hardly corresponds with the one in face-to-face communication, it provides a virtual space for the users to share thoughts, beliefs, actions or audio-visual contents. Without magnifying its capabilities, social media is a prominent means of communication in today's world. Consequently, communication between individuals from different cultural backgrounds takes its share from this transformation. Scholars agree that intercultural communication and new media are required to be focused together as a research area (Amant, 2002; McEwan and Sobre-Denton, 2011; Chen, 2012; Shutter, 2012).

From this perspective, focusing on Facebook groups of expatriates, this study attempts to trace intercultural communication among members. It is aimed to see how Facebook groups are used by expats. Findings of the study revealed that expats generally use the space of social network group for survival in a new country. Expats, who due to work and live in a different culture, may naturally face with many changes and challenges of being in a different environment. Since expats are the center of global business life, individual or corporate based business forms a topic of communication in Facebook groups. Shelton and Skalski (2013) emphasize the importance of word-of-mouth marketing through SNS for business initiatives (p. 341). Advertising, publicity, and announcements are highly used by individuals or organizations in order to develop business. Another prominent topic in social media is information seeking. Facebook groups are considerably used as information sources. As Farh and others (2010) proposes, expats interact with other expats while seeking informational support. Hereby, the study findings of examined social network groups reveal that expats often use these sites to gather information from other members who are supposed to have experience in the host country and city.

Although the length of stay of the members can be divergent, SNS provide users to maintain ties with other expats. Such virtual networks may be an area of interpersonal connection and learning about the surroundings (Croucher, 2011). Therefore, the matter of survival in a different environment leads expats to communicate with other members about living, working, entertaining, and for information gathering. Although communication contentrarely involves topics relating to intercultural communication, such as cultural adaptation, the examined Facebook groups function asan area of intercultural relationship that may be sustained outside of the virtual space through event organizations, social, sportive, cultural activities, and business relationships.

Finally, intercultural relationship discussed in this paper is confined to the content of two SNS groups, firstly the "Expats in Istanbul" during a period of one month, secondly the "Expats in Amsterdam" during a shorter period that includes double size data. Further research will contributein intercultural communication by identifyingcommunication patterns, flows, problems and solutions in relation with the new media. 


\section{References}

[1] Amant, K. St., "When cultures and computers collide rethinking computer-mediated communication according to international and intercultural communication expectations", Journal of Business and Technical Communication, 16 (2), pp. 196-214, 2002. http://dx.doi.org/10.1177/1050651902016002003

[2] Batardière, M., "Promoting critical thinking in online intercultural communication", The EuroCALL Review, 23(1), pp. 3-10, 2015. http://dx.doi.org/10.4995/eurocall.2015.4562

[3] Black, J. S., "The relationship of personal characteristics with the adjustment of Japanese expatriate managers", MIR: Management International Review, 30 (2), pp. 119-134, 1990.

[4] Brooks, C. F. and Pitts, M. J., "Communication and identity management in a globally-connected classroom: An online international and intercultural learning experience", Journal of International and Intercultural Communication, pp. 1-17, 2015.

[5] Caligiuri, P. M., "Selecting expatriates for personality characteristics: A moderating effect of personality on the relationship between host national contact and cross-cultural adjustment", MIR: Management International Review, 40 (1), pp. 61-80, 2000.

[6] Caligiuri, P. M., Tarique, I. and Jacobs, R., "Selection for international assignments." Human Resource Management Review 19.3, pp. 251-262, 2009.

http://dx.doi.org/10.1016/j.hrmr.2009.02.001

[7] Chen, G. M., "The Impact of New Media on Intercultural Communication in Global Context", China Media Report Overseas, 9(1), 2013.

[8] Cho, H. and Lee, J.S., "Collaborative information seeking in intercultural computer-mediated communication groups: Testing the influence of social context using social network analysis." Communication Research, 35 (4), pp. 548-573, 2008. http://dx.doi.org/10.1177/0093650208315982

[9] Coffey, A. J., Kamhawib, R., Fishwickc, P. and Hendersond, J., "New media environments' comparative effects upon intercultural sensitivity: A five-dimensional analysis.", International Journal of Intercultural Relations, 37 (5), pp. 605-627, 2013. http://dx.doi.org/10.1016/j.ijintrel.2013.06.006

[10] Collier, M. J., "Intercultural communication competence: Continuing challenges and critical directions", International Journal of Intercultural Relations, 48, pp. 9-11, 2015. http://dx.doi.org/10.1016/j.ijintrel.2015.03.003

[11] Clausen, L., Zolner, M., Soederberg A. M. and Worm, V., "Cultural intelligence as a strategic resource in multicultural teams." Proceedings of the 2009 international workshop on Intercultural collaboration. ACM, 2009, pp. 211-214. http://dx.doi.org/10.1145/1499224.1499258

[12] Croucher, S. M., "Social networking and cultural adaptation: A theoretical model. Journal of International and Intercultural Communication”, 4 (4), pp. 259-264, 2011.

http://dx.doi.org/10.1080/17513057.2011.598046

[13]Deardorff, D. K., "Identification and assessment of intercultural competence as a student outcome of internationalization", Journal of studies in international education, 10 (3), pp. 241-266, 2006. http://dx.doi.org/10.1177/1028315306287002

[14]Deng L. and Gibson, P., "A qualitative evaluation on the role of cultural intelligence in cross-cultural leadership effectiveness", International journal of leadership studies, 3 (2), pp. 181-197, 2008.

[15] Devran, Y., "Global Class: New media and intercultural communication", Journal of Arab \& Muslim Media Research, 3 (1-2), pp. 89-97, 2010. http://dx.doi.org/10.1386/jammr.3.1-2.89_1

[16]Elo, S. and Kyngäs, H., "The qualitative content analysis process." Journal of advanced nursing 62.1, pp. 107-115, 2008. http://dx.doi.org/10.1111/j.1365-2648.2007.04569.x

[17]Farh, C. I. C., Bartol, K. M., Shapiro, D. L. and Shin, J., "Networking abroad: A process model of how expatriates form support ties to facilitate adjustment." Academy of Management Review, 35 (3), pp. 434-454, 2010. http://dx.doi.org/10.5465/AMR.2010.51142246

[18] Graf A. and Harland, L. K., "Expatriate selection: evaluating the discriminant, convergent, and predictive validity of five measures of interpersonal and intercultural competence”, Journal of Leadership \& Organizational Studies, 11 (2), pp. 46-62, 2005.

http://dx.doi.org/10.1177/107179190501100206

[19] Hall, E. T., The Silent Language, 1959, New York: Doubleday. 
[20] Hammer, M. R., Gudykunst, W. B. and Wiseman, R. L., "Dimensions of intercultural effectiveness: An exploratory study." International Journal of Intercultural Relations, 2 (4), pp. 382-393, 1979.

http://dx.doi.org/10.1016/0147-1767(78)90036-6

[21] Hsieh, H.F. and Shannon, S. E., "Three approaches to qualitative content analysis." Qualitative health research 15.9, pp. 1277-1288, 2005. http://dx.doi.org/10.1177/1049732305276687

[22] Huff, K. C., "Language, cultural intelligence and expatriate success", Management Research Review, 36 (6), pp. 596612, 2013. http://dx.doi.org/10.1108/01409171311325750

[23] Koh, C., Joseph, D. and Ang, S., "Cultural intelligence and collaborative work: intercultural competencies in global technology work teams", In Proceedings of the 2009 international workshop on Intercultural collaboration, 2009, pp. 261-264. http://dx.doi.org/10.1145/1499224.1499271

[24] Kolbe, R. H. and Burnett, M. S., "Content-analysis research: An examination of applications with directives for improving research reliability and objectivity", Journal of consumer research, 18 (2), pp. 243-250, 1991. http://dx.doi.org/10.1086/209256

[25] Krippendorff, K., "Content analysis", In E. Barnouw, G. Gerbner, W. Schramm, T. L. Worth, \& L. Gross (Eds.), International encyclopedia of communication, vol. 1, pp. 403-407, New York, NY: Oxford University Press, 1989, Retrieved from http://repository.upenn.edu/asc_papers/226

[26] Krippendorff, K. "Measuring the Reliability of Qualitative Text Analysis Data", Quality and Quantity, 38 (6), pp. 487800, December 2004.

[27]Lang, A., "Exploring the potential of social network sites in relation to intercultural communication, Arts and Humanities in Higher Education", sagepub.co.uk/journalspermissions.nav vol II (I-2), pp. 120-139, 2010.

[28] Marsh, E. E. and White, M. D., "Content analysis: A flexible methodology”, Library trends, 55(1), pp. 22-45, 2006. http://dx.doi.org/10.1353/lib.2006.0053

[29] McEwan B. and Sobre-Denton, M., "Virtual cosmopolitanism: Constructing third cultures and transmitting social and cultural capital through social media", Journal of International and Intercultural Communication, 4 (4), pp. 252-258, 2011. http://dx.doi.org/10.1080/17513057.2011.598044

[30] Peltokorpi, V., "Intercultural communication in foreign subsidiaries: The influence of expatriates' language and cultural competencies", Scandinavian Journal of Management, 26 (2), pp. 176-188, 2010. http://dx.doi.org/10.1016/j.scaman.2010.02.003

[31] Thomas, R. et al. "Beyond general intelligence (IQ) and emotional intelligence (EQ): The role of cultural intelligence (CQ) on cross-border leadership effectiveness in a globalized world", Journal of Social Issues, 67 (4), pp. 825-840, 2011. http://dx.doi.org/10.1111/j.1540-4560.2011.01730.x

[32] Seidenspinner M. and Theuner, G., "Intercultural aspects of online communication a comparison of mandarinspeaking, US, Egyptian and German user preferences”, Journal of Business Economics and Management, 8 (2), pp. 101-109, 2007.

[33] Semetko H. A. and Valkenburg, P. M., "Framing European politics: A content analysis of press and television news", Journal of communication, 50 (2), pp. 93-109, 2000. http://dx.doi.org/10.1111/j.1460-2466.2000.tb02843.x

[34] Shelton A. K. and Skalski, P., "Blinded by the light: Illuminating the dark side of social network use through content analysis", Computers in Human Behavior, vol. 33, pp. 339-348, 2014. http://dx.doi.org/10.1016/j.chb.2013.08.017

[35] Shuter, R., "Intercultural new media studies: The next frontier in intercultural communication.", Journal of Intercultural Communication Research 41.3. p. 221, 2012.

[36] Spitzberg, B. H., "A model of intercultural communication competence", Intercultural communication: A reader, vol. 9, pp. 375-387, 2000.

[37] Stahl, G. K., Maznevski, M. L., Voigt A. and Jonsen, K., "Unraveling the effects of cultural diversity in teams: A meta-analysis of research on multicultural work groups", Journal of international business studies, 41 (4), pp. 690$709,2010$. http://dx.doi.org/10.1057/jibs.2009.85

[38] Stening, B. W. and Hammer, M. R., "Cultural baggage and the adaption of expatriate American and Japanese managers", MIR: Management International Review, 1992, 32 (1), pp. 77-89, 1992

[39] Toyokawa, N., "The function of the social network formed by Japanese sojourners' wives in the United States", International journal of intercultural relations, 30 (2), pp. 185-193, 2006. http://dx.doi.org/10.1016/j.ijintrel.2005.05.016 
[40] Tung, R. L., "Selection and training of personnel for overseas assignments", Columbia Journal of World Business, 16 (1), pp. 68-78, 1981.

[41] Tung, R. L., "Managing cross-national and intra-national diversity", Human Resource Management, 32 (4), pp. 461477, Winter 1993.

[42] Von Koppenfels, A. K., "Migrants or Expatriates? : Americans in Europe”. Houndsmills and New York: Palgrave Macmillan, 2014. http://dx.doi.org/10.1057/9781137316301

[43] Wang, C-M., "Using Facebook for cross-cultural collaboration: The experience of students from Taiwan", Educational Media International, 49 (1), pp. 63-76, 2012. http://dx.doi.org/10.1080/09523987.2012.662625

[44] Wang, Z., Walther, J. B. and Hancock, J. T., "Social Identification and Interpersonal Communication in ComputerMediated Communication: What You Do Versus Who You Are in Virtual Groups", Human Communication Research, 35 (1), pp. 59-85, 2009. http://dx.doi.org/10.1111/j.1468-2958.2008.01338.x

[45]Zhang, Y., "Expatriate Development for Cross-Cultural Adjustment: Effects of Cultural Distance and Cultural Intelligence", Human Resource Development Review, 12 (2), pp. 177-199, 2012. http://dx.doi.org/10.1177/1534484312461637 